\title{
Integrating Human Behavior and Safety Measure into Evacuation Route Planning in a Volcanic Crisis
}

\author{
Budhi Sholeh Wibowo ${ }^{*}$, Budi Hartono ${ }^{1^{*}}$
}

\begin{abstract}
Many traditional methods in evacuation route planning are motivated by the operational objective, such as total travel/clearance time. Little attention has been given to the human factor and the safety aspect of the evacuees during the planning phase. Our study aims to propose a simple yet practical route planning method that simultaneously considers human behavior, safety factor, and the travel time in a volcanic crisis context. The planning model is developed based on the shortest-path problem with a joint-cost parameter representing the three aspects. We present a large-scale street network in Merapi volcano as a case study. The result implies that employing a joint-cost parameter is effective for creating an evacuation route that is reasonably safe and in line with human cognition in navigation. The finding offers practical insights for the stakeholders as part of the greater effort to develop a systematic disaster management plan.
\end{abstract}

Keywords: Evacuation route, disaster management, human behavior, volcanic crisis.

\section{Introduction}

Being positioned on the pacific ring of fire, Indonesia has to cope with the continual risk of volcanic eruptions, earthquakes, floods, and tsunamis. As one of the strategic responses, the Government of Indonesia developed a National Disaster Management Plan to increase public emergency response through several risk mitigation programs. One of the government's leading programs is to develop reliable evacuation routes in all vulnerable areas in Indonesia. Evacuation routes have been considered as an effective way to minimize fatalities or injuries in facing natural disasters [1]. The evacuation routes act as the primary reference for the evacuees to move from threatened area to a safer place in case of emergency.

Many studies on the evacuation route planning includeed travel time as the key performance indicator (e.g., [2,3,4]). The choice of travel time as the primary indicator is reasonable since an evacuation's objective is to move people to a safer place as quickly as possible so that human casualties can be avoided. It is especially true in the case of fires and earthquakes. However, the evacuation in a volcanic crisis has distinct characteristics compared to other types of evacuation. First, the eruption can occur randomly and subsequently trigger other threats such as pyroclastic flows, lava, and ejected rocks. This crisis can last for days or even weeks. Consequently, the evacuation is often executed gradually over a long period.

\footnotetext{
${ }^{1}$ Faculty of Engineering, Mechanical and Industrial Engineering Department, Universitas Gadjah Mada, Jl. Grafika 2, Yogyakarta 55281, Indonesia. Email budhisholehwibowo@ugm.ac.id, boed@ugm.ac.id

* Corresponding author
}

Second, lahars and floods from the eruption mostly flow through waterways, which can endanger the evacuation process since many of the main streets typically reside alongside the rivers. Therefore, the evacuees' safety when traversing the evacuation route should also be considered during the planning process.

Besides the safety factor, human behavior also plays an essential role during an evacuation. When selecting a route, human often relies on their perception of the street networks. This perception is known in the literature as the cognitive distance [5,4]. The cognitive distance concerns people's perception of the distance between two geographical points when the destination cannot be seen [7]. Such a perception is often constructed by heuristics and distorted by human's limited knowledge of geographical landmarks. For instance, several studies have found that people perceived a path to be cognitively shorter if it had fewer turns, even if the physical distance traversed was longer $[8,9,10]$. In many navigation systems, cognitive distance has also been included to minimize instructions' complexity [11]. Unfortunately, this feature has not been widely adopted in evacuation route planning. In case of an emergency, people often rely on their intuition to navigate their way. They would easily get confused when the suggested route is different from what they perceive as the best route. One of the possible outcomes is that they decide to ignore the suggested route and prefer to follow their intuition without knowing that it may lead them to misfortune.

The discussion above leads to the hypothesis that integrating safety measures and human behavior could lead to a safer and more practical evacuation 
route. Our study proposes a new method to plan an evacuation route for a volcanic emergency, which simultaneously considers: (a) distance, (b) safety, and (c) human cognition. The planning itself is modeled as a shortest path problem where the objective is to create a simple, quick, and reliable route for the evacuees. Merapi Volcano in Indonesia was selected as the case study to demonstrate the practicality of the proposed method.

The contributions of the study are twofold. From the academic perspective, it extends the extant body of knowledge pertaining to the modeling of evacuation routes by jointly considering three unique measures, as mentioned earlier. The proposed model also offers a more comprehensive and realistic analysis than previous studies. From a practical point of view, the study provides some useful recommendations for Merapi planners. It also offers transferable insights for volcano-related evacuation planners and decisionmakers beyond the Mount Merapi setting.

The remaining of the paper is organized as follows. First, it reviews the literature on evacuation route planning. Then, the study area and methods are presented and described. Next, the numerical experiments and the findings from the study are discussed. The paper concludes with the managerial implication and direction for further research.

\section{Methods}

Previous studies on evacuation route planning were mostly examined based on the operational perspective and rarely based on safety considerations. Stepanov and Smith [2] modeled the evacuation route planning using a mathematical integer program to cope with congestion and time delays on street links. Their model includes blocking probability on the street links to minimize the total clearance time. Lim, et al. [4] evaluated the relationship between the travel time and the congestion probability in the evacuation route. They concluded that the minimization of travel time for an evacuation plan should not be the only objective for a planner, especially when the capacity and street traffic play critical variables in the problem. Baou et al. [12] proposed a model to consider the disabled population in the evacuation plan. They found that evacuating people with disabilities has a significant impact on total evacuation time. In contrast to these studies, our study proposed another perspective in the evacuation route planning by considering the potential hazards along the evacuation route to ensure the evacuees' safety. The premise is that people should follow the safest evacuation route to minimize possible injuries and accidents during an evacuation.
Further, several studies on human cognition have indicated that human possesses a unique behavior in navigation. Human has been known to rely on their perception of street networks during navigation $[5,6]$. Golledge [13] conducted a rich experiment to investigate human criteria on path selection. He found that most subjects follow a path with the fewest turns instead of the shortest path. Using traces of millions of GPS data in Australia, Zhu and Levinson [14] validate that most people did not follow the shortest path when navigating to a specific place. These findings imply that human factor should not be overlooked in route planning. Their behavior is essential to develop a practical and realistic route for a massive evacuation as in the volcanic crisis.

A limited number of studies have included human cognition in evacuation planning. Pires [15] used a Bayesian Belief Network to model human decision in case of fire emergencies. His model includes stress level, time constraint, and attention level to determine the best time to evacuate. Lee, et al. [16] performed an experiment to evaluate people's walking speed during an evacuation. They found that counter-flow events as the main factor that slows down the walking speed during an evacuation and thus should be minimized. Pan et al. [17] developed a multi-agent framework for studying human and social behaviors during an emergency. Their model includes a random walk, seeking behavior, and collision avoidance behavior, which successfully reproduces emergent human social behaviors, such as competitive, queuing, and herding behaviors at the microscopic level. Jumadi et al. [18] used an agentbased model to simulate human evacuation decisions (to-stay/to-leave) during a volcanic crisis in mount Merapi. They found that the occurrence of the explosion was the most important motivation for people to evacuate. By using an experiment, Ding and Sun [19] found that opinion leaders had a limited influence choice of evacuation route, and most people followed the path of those ahead of them.

Nevertheless, none of the previous studies has simultaneously considered human behavior and safety factors during an evacuation. To our knowledge, this is the first study that simultaneously integrates both factors into an evacuation route planning in the context of a volcanic emergency. The finding from this study provides the authorities with a novel method to generate a simple, fast, and reliable evacuation route in a volcano.

\section{Study Area}

This study was conducted based on the Merapi volcano setting, which is one of the most active volcanoes in Indonesia. The volcano is administratively located in the Sleman Regency, approximately 28 kilometers north of Yogyakarta city. The regency itself is inhabited by 2.4 million people, 


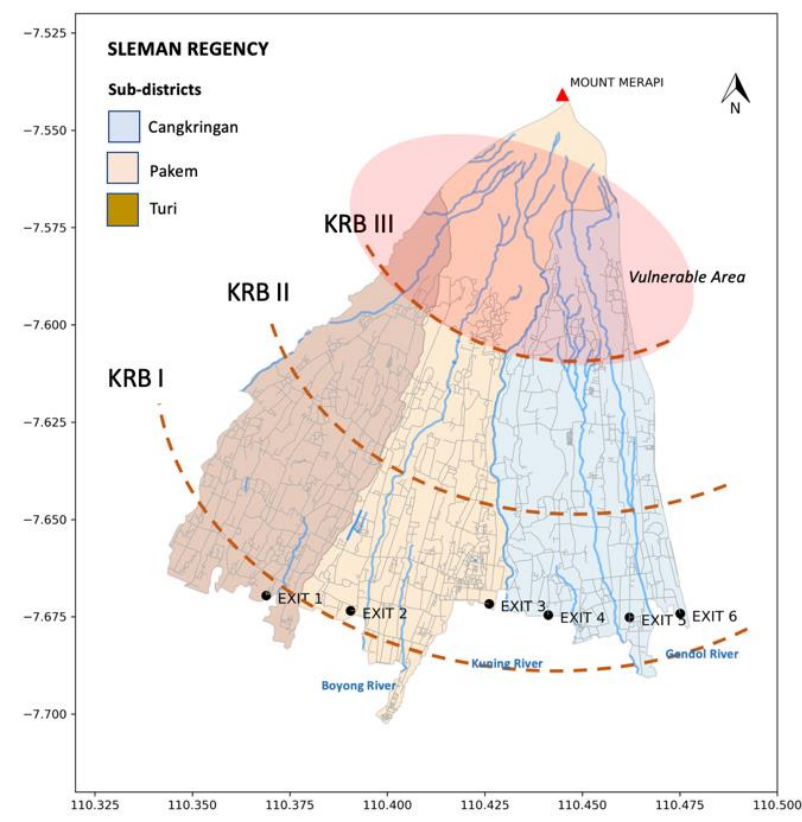

Figure 1. Map of the study area

where thousands of them live on the volcano's flanks. Merapi has a typical eruption period of four years, and the eruption is often followed by pyroclastic flows, fast-moving currents of hot gas, and volcanic matters flowing from the top of a volcano. The pyroclastic flows can travel as far as $15 \mathrm{~km}$ from the source with a speed of $100 \mathrm{~km} / \mathrm{h}$ and temperature of about 1,000 ${ }^{\circ} \mathrm{C}$ [20]. The flows have frequently caused severe casualties to the population nearby. In 1930, the pyroclastic flowed from Mount Merapi was reported to destroy thirteen villages and killed more than 1,300 people [21]. More recently, in 2010, the eruption has also caused 367 fatalities and a displacement of more than 400,000 people living within a radius of 20 kilometers from the summit [22].

Three subdistricts in the regency are selected as the study area, namely Cangkringan, Pakem, and Turi. These three sub-districts have been considered as the most vulnerable area during Merapi eruptions [23]. The Regional Agency for Disaster Management (BPBD) in Sleman has defined three dangerous zones (Kawasan Rawan Bencana, KRB) for Merapi, ranked from KRB I (low level of threats) to KRB III (high level of threats). The zone division is based on the geological structure, potential hazards, and proximity to the volcano's summit. Mei et al. [1] summarized the potential hazards in each dangerous zones. KRB III includes areas near the volcano and is frequently troubled by lava flows, pyroclastic flows, and ejected rock fragments. KRB II may also be affected by the same threats as KRB III, although the frequency and the severity are lower. KRB I has the lowest hazards since it is bothered only by lahar and floods. The map of the zone division in the study area is depicted in Figure 1.
Besides the dangerous zones, the agency also identified three extremely hazardous rivers during the Merapi crisis, i.e., Boyong, Kuning, and Gendol rivers [23]. These rivers often carry lahars and floods from the eruptions, which can endanger the populations nearby. According to Wasito [23], an area is considered safe from lahars and floods when situated at least 300 meters from the rivers. This information can serve as a basis to determine the risks in the street networks so that the planner can avoid including dangerous path in the proposed evacuation route.

\section{Reseach Methods}

We collected the streets and the waterways data in the study areas from Open Street Map. Using OSMNx software, we modeled the streets and the waterways as a multi-directed graph $\mathrm{G}(\mathrm{V}, \mathrm{E})$, where $\mathrm{V}$ denotes a set of vertices representing the crossroads, and $\mathrm{E}$ denotes a set of edges represents the streets (Boeing, [24, 25] ). The acquired networks consist of 2,507 nodes with 6,554 edges. Every edge contains information about the length, the width, the lanes, and the street's bearing. In this study, we only include streets that have a minimum width of 6 meters. The requirement is necessary to make sure that the road capacity is enough to carry the evacuation flow.

In this study, the model of evacuation route planning was modeled based on the shortest path problem. The problem involves finding the best path between sources and targets that minimize the total cost along the path $[26,27]$. By using graph theory, the problem can be easily modeled as a linear program. Given a directed graph $G(V, E)$ with source node $s$ and target node $t$, and cost $w_{i j}$ for each edge $(i, j)$ in $E$, consider an optimization problem with decision variable $x_{i j}$. Objective function:

$\operatorname{minimize} \sum_{i, j \epsilon V} w_{i j} x_{i j}$

Decision variable:

for all $i: \quad \sum_{j} x_{i j}-\sum_{j} x_{j i}=\left\{\begin{array}{cc}1 & \text { if } i=s \\ -1 & \text { if } i=t \\ 0 & \text { otherwise }\end{array}\right.$

Constraint:

$x_{i j} \geq 0$

Equation (1) serves as the objective function which aims to minimize the cost along the path. Equation (2) is the decision variable that decides whether an edge $(i, j)$ is part of the selected path. Lastly, Equation (3) acts as a constraint to maintain that the selected edges form a path from source $s$ to target $t$.

In the context of Merapi Volcano, we define the sources to be all the crossroads in KRB III, and the targets are the exit points available in KRB I. Therefore, the shortest path problem has multiple 
sources and multiple targets [28]. The model aims to find the best path from a set of sources $S=$ $\left\{s_{1}, s_{2} \ldots s_{n}\right\}$ to the nearest destination in the target set $T=\left\{t_{1}, t_{2} \ldots t_{m}\right\}$. Dijkstra algorithm was implemented to solve the path-finding problem. The complete procedure to solve the problem based on the shortest path analysis is as the following:

Step 1 : Define the vulnerable area, exit points, and all the available road networks in the study area

Step 2 : Save the road networks as graph $\mathrm{G}(\mathrm{V}, \mathrm{E})$ where $\mathrm{V}$ is the road intersection, and $\mathrm{E}$ is the road.

Step 3 : Define the cost $w_{i j}$ for every edge $(i, j)$ in the graph $\mathrm{G}$

Step 4 : Identify the source nodes $\mathrm{S}$ and target nodes $\mathrm{T}$ in the graph $\mathrm{G}$

Step 5 : Run the Dijkstra's algorithm to find all the shortest path $P$ from the source nodes $\mathrm{S}$ to all the target nodes in $\mathrm{T}$

Step 6 : Measure the path length for each shortest path $\mathrm{p}$ in $P$

Step $7 \quad$ : For each source node s, compare the length of the shortest path $p$ to target nodes in $\mathrm{T}$ and save only the path with the minimum cost

Note that the shortest path in the network can be defined based on several cost measures. In this study, we use three different costs to select the shortest path, namely: (1) physical distance, (2) risk probability, and (3) path complexity. The details of the cost measures are discussed in the following subsections.

\section{Physical Distance}

Physical distance is the most common measure in the shortest path problem and its variants. The problem considers the physical distance of a street from node $i$ to node $j$ in the graph G. Let denotes $d_{i j}$ as the physical distance of the street $(i, j)$. We derived the value of $d_{i j}$ from OSM. Assuming that the physical distance is associated positively with travel time, the quickest evacuation route can be determined by selecting the shortest path in the network.

\section{Risk Probability}

We define risk probability as a variable that measures the level of threats along the path. Generally, the closer the evacuation path to the volcano and the river, the higher the risk for the evacuees. Based on this rule, we proposed two simple criteria to determine the risk probability of a path, as shown in Table 1.
Table 1. Risk probability of a street

\begin{tabular}{crc}
\hline $\begin{array}{c}\text { Distance to } \\
\text { volcano's } \\
\text { summit }\end{array}$ & $\begin{array}{c}\text { Distance to a } \\
\text { nearby river }\end{array}$ & $\begin{array}{c}\text { Risk probability } \\
\left(\boldsymbol{r}_{\boldsymbol{i} \boldsymbol{j}}\right)\end{array}$ \\
\hline \multirow{3}{*}{$0-10 \mathrm{~km}$} & $0-100 \mathrm{~m}$ & 0.950 \\
& $100-300 \mathrm{~m}$ & 0.925 \\
& $>300 \mathrm{~m}$ & 0.900 \\
\hline \multirow{2}{*}{$10-15 \mathrm{~km}$} & $0-100 \mathrm{~m}$ & 0.750 \\
& $100-300 \mathrm{~m}$ & 0.625 \\
& $>300 \mathrm{~m}$ & 0.500 \\
\hline \multirow{3}{*}{$15-20 \mathrm{~km}$} & $0-100 \mathrm{~m}$ & 0.500 \\
& $100-300 \mathrm{~m}$ & 0.250 \\
& $>300 \mathrm{~m}$ & 0.010 \\
\hline
\end{tabular}

Let us denotes $r_{i j}$ as the risk probability in edge $(i, j)$. The risk probability $r_{i j}$ is measured based on the proximity of the path to the volcano and the nearby rivers. The higher the value of $r_{i j}$, the higher the risks to traverse street $(i, j)$. Thus, based on this measure, selecting a set of streets that minimizes the total risk probability along the route can determine the safest path in the street network. To do so, we replace the cost measure in the shortest path problem with $w_{i j}^{R}$, representing the risk of traversing the street $(i, j)$.

$w_{i j}^{R}=r_{i j} d_{i j}$

\section{Path Complexity}

During an emergency, people tend to navigate toward specific direction which is believed to be a safe reference. For instance, we found that many people in the study area intuitively ran to the south to avoid hazards from the volcano. In this case, the south serves as the safe reference during a volcanic emergency. The safe reference serves as a simple rule that is believed to be the right course to avoid the source of danger.

Based on this observation, we proposed a new cost measure, namely path complexity. This cost represents the total angular deviation of a path to the safe reference $a^{\circ}$. We assume that the evacuees prefer a path that is in line with the course of reference (in this case, the south). Let us define the street bearing $b_{i j}$ as the angle of a street relative to the north. The path complexity $w_{i j}^{a}$ is measured as follows:

$w_{i j}^{a}=\left[\frac{180^{\circ}-\operatorname{abs}\left(\operatorname{abs}\left(a^{\circ}-b_{i j}\right)-180^{\circ}\right)}{180^{\circ}}\right] d_{i j}$

Equation (5) ensures that the path complexity only takes the smallest deviation between the angle of reference and the street bearing. 
(a) Scenario 1: Shortest Paths

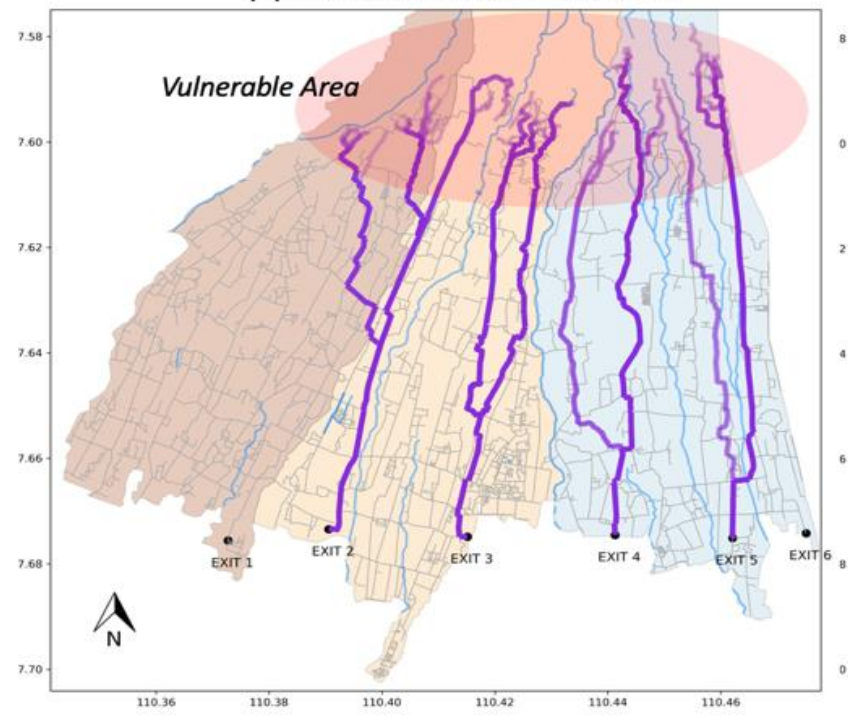

(c) Scenario 3: Simplest Paths

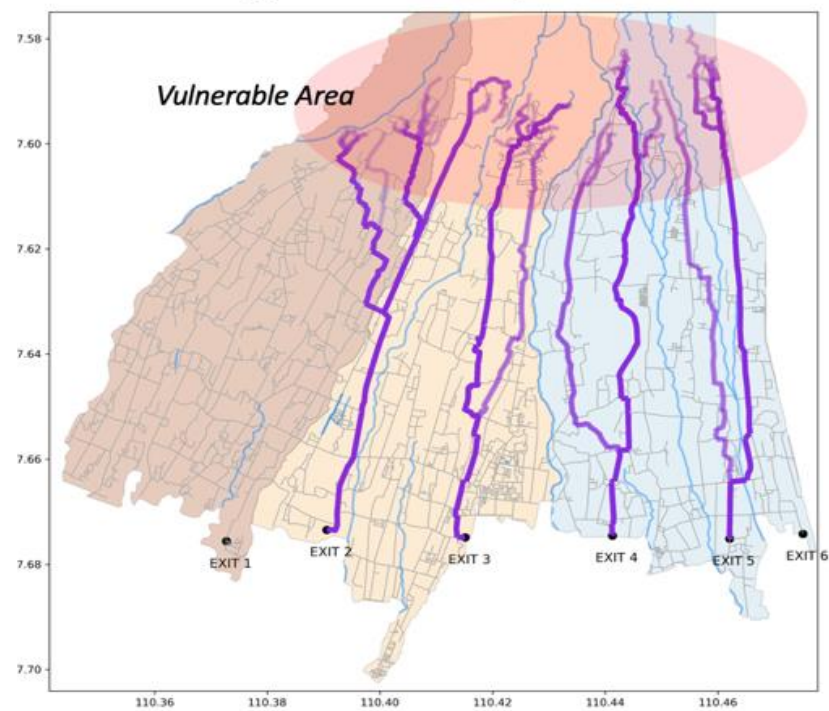

(b) Scenario 2: Safest Paths

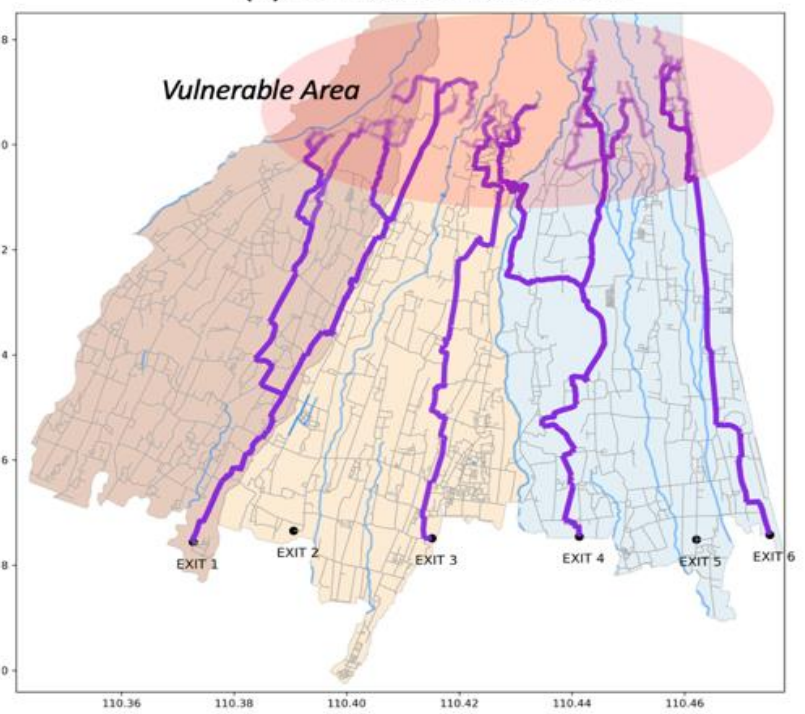

(d) Scenario 4: Joint-Cost Paths

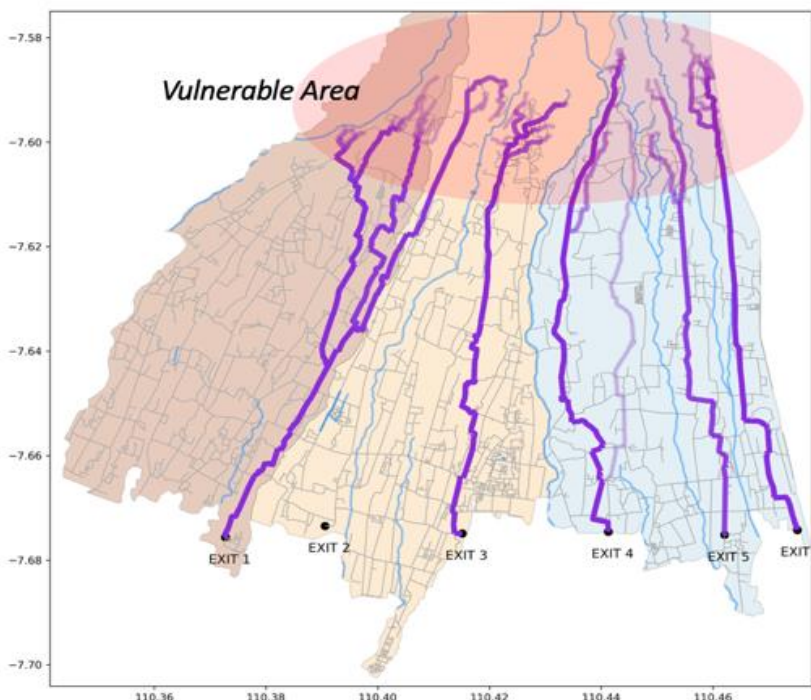

Figure 2. Evacuation routes based on different scenario: (a) shortest path; (b) simplest path; (c) safest path; and (d) joint cost path

By using this measure, a path navigates straight to the angle of reference will have a smaller path complexity, leading to a simpler path.

\section{Joint-cost Measure}

To simultaneously consider human cognition and safety factors in the route planning problem, we combine the risk measure $w_{i j}^{a}$ and complexity measure $w_{i j}^{R}$ into a joint-cost $w_{i j}^{C}$. The joint cost aims to guide the path selection process in the shortest path model to prioritize less risk and less complex paths.

$w_{i j}^{C}=w_{i j}^{R} \times w_{i j}^{a}$

\section{Results and Discussions}

\section{Numerical Experiments}

To analyze the performance of the proposed method, we created a numerical experiment with four scenarios based on different cost measures. For simplicity, we refer to each scenario as the "shortest path," the "safest path," the "simplest path," and the "joint-cost path." The result is shown in Figure 2. The routes in Figure 2a and Figure 2c show a high similarity between the shortest and the simplest path. The high similarity is likely caused by the existing cardinal pattern in the street network, making it 
Table 2. Comparison of evacuation routes performance

\begin{tabular}{lcccc}
\hline $\begin{array}{l}\text { Cost } \\
\text { Parameter }\end{array}$ & $\begin{array}{c}\text { Shortest } \\
\text { Paths }\end{array}$ & $\begin{array}{c}\text { Safest } \\
\text { Paths }\end{array}$ & $\begin{array}{c}\text { Simplest } \\
\text { Paths }\end{array}$ & $\begin{array}{c}\text { Joint- } \\
\text { Cost } \\
\text { Paths }\end{array}$ \\
\hline Distance & $0 \%$ & $26 \%$ & $2 \%$ & $8 \%$ \\
Risks & $34 \%$ & $0 \%$ & $38 \%$ & $15 \%$ \\
Complexity & $1 \%$ & $40 \%$ & $0 \%$ & $16 \%$ \\
\hline
\end{tabular}

Note: the costs are presented in percentage relative to the minimum value in the cost category

easy for people to find a direct path to the south. Besides, we also found that the shortest path in the network does not share many routes with the safest path. As shown in Figure 2b, the safest path has distinct routes than the shortest and simplest paths. The safest path is shown to have more complex routes with several turns to minimize the potential hazard along the route. Consequently, it results in a longer route than the routes in the simplest and shortest paths. Figure $2 \mathrm{~d}$ exhibits a more balanced route which is developed based on the joint-cost parameters. The route does not only possess fewer turns, but it also avoids direct encounters with the rivers to minimize the hazards along the route. This result suggests that the joint-cost function is a promising measure for evacuation route planning. It could help planners to build a quick, simple, and safe route for the evacuees.

Table 2 summarized the performance comparison between scenarios in terms of total distance, path complexity, and aggregated risks. To simplify the comparison, we standardized the total cost based on the minimum value for each cost category. The result suggests that there are notable trade-offs between the safest path and the simplest path. The best compromise is found when the route is optimized based on the joint-cost. Although the joint-cost path does not come as the best performer in all cost categories, it can reasonably moderate the cost tradeoff. Note that the joint-cost path is only $8 \%$ longer from the shortest path, but they have $19 \%$ fewer risks than the shortest path. They also have $24 \%$ fewer turns than the safest path, making them more practical during an emergency.

\section{Conclusions}

Our study aims to propose a method to integrate safety measures and human behavior into evacuation route planning. This was not an easy task since there is an eminent trade-off between the simplest and the safest path. Our experiments show that the simplest path often takes a risky route, which could endanger the evacuees. In contrast, the safest path tends to provide a complicated route, which is hard to follow. A more balanced solution can be achieved when both risk probability and path complexity are incorporated as a joint-cost measure. Using numerical simulation, we showed that this new measure effectively provides a good compromise between distance, risks, and complexity.

The findings from this study offer some practical implications for related stakeholders. First, the local authority should not let people in mount Merapi evacuate independently without visible guidance. Their limited knowledge of the street networks could lead them to misfortune. Second, the route planner should not only consider the total travel time as the objective. Such a measure often neglects the potential hazards along the evacuation route. Integrating safety measures and human behavior into the route planning process can help planners develop a safer and practical route that is in line with human cognition in navigation.

There are some limitations to the study. First, the study did not take into account the potential traffic jam in the evacuation route. Bottleneck analysis is indeed an important issue that should be considered during the route planning process, especially in case of fires or earthquakes. However, in the volcanic emergency setting, the evacuation is often performed gradually over a long period, which dissolves the traffic into smaller batches. Therefore, the exclusion of bottleneck analysis in this study can be safely assumed.

Although the proposed method in this study is relatively simple, it also opens many opportunities to be extended into a more complex model. For instance, the path complexity and the risk measure can be incorporated into the capacity constraint route planner, which considers the network's bottleneck probability. The risk factor can also be enhanced by considering the steepness of the road. Further, one can include the joint-cost measures into an agentbased model to evaluate evacuees' microscopic behavior in a volcanic emergency.

\section{References}

1. Mei, E. T. W., Lavigne F., Picquout, A., de Belizal, E., Brunstein, D., Grancher, D., Sartohadi, J., Cholik, N., and Vidal, C., Lessons Learned from the 2010 Evacuations at Merapi Volcano, Journal of Volcanology Geothermal Research, 261, 2013, pp. 348-365.

2. Stepanov, A. and Smith, J. M. G., Multi-objective Evacuation Routing in Transportation Networks, European Journal of Opererational Research, 198(2), 2009, pp. 435-446.

3. Syiko, S. F., Ayu T., R, and Yudono, A., Evacuation Route Planning in Mount Gamalama, Ternate Island-Indonesia, Procedia Enviromental Science, 17, 2013, pp. 344-353. 
4. Lim, G. J., Rungta, M., and Baharnemati, M. R., Reliability Analysis of Evacuation Routes under Capacity Uncertainty of Road Links, IIE Transaction, Institute of Industrial Engineering, 47(1), 2015, pp. 50-63.

5. Turner, A., and Dalton, N., A Simplified Route Choice Model using the Shortest Angular Path Assumption, 8th International Conference Geo Computation, 2005, [Online]. Available: http://www.geog.leeds.ac.uk/groups/geocomp/200 5/Turner.pdf.

6. Jayasinghe, A., Sano, K., Kasemsri, R., and Nishiuchi, H., Travelers' Route Choice: Comparing Relative Importance of Metric, Topological and Geometric Distance, Procedia Engineering, 142, 2016, pp. 18-25.

7. Montello, D. R., The Measurement of Cognitive Distance: Methods and Construct Validity, Journal of Enviromental. Psychology, 11(2), 1991, pp. 101-122.

8. Sadalla, E. K., and Magel, S. G., The Perception of Traversed Distance, Enviromental Behaviour, 12(1), 1980, pp. 65-79.

9. Zhou, Y., Wang, W., He, D., and Wang, Z., A Fewest-turn-and-shortest Path Algorithm based on Breadth-first Search, Geo-Spatial Information Science, 17(4), 2014, pp. 201-207.

10. Jiang, B., and Liu, X., Computing the Fewestturn Map Directions based on the Connectivity of Natural Roads, International Journal of Geographical Information Science, 25(7), 2011, pp. 1069-1082.

11. Duckham, M., and Kulik, L., Simplest' Paths: Automated Route Selection for Navigation," in Lecture Notes in Computer Science (Including Subseries Lecture Notes in Artificial Intelligence and Lecture Notes in Bioinformatics), 2825, 2003, pp. 169-185.

12. Baou, E., Koutras, V. P., Zeimpekis, V., and Minis, I., Emergency Evacuation Planning in Natural Disasters under Diverse Population and Fleet Characteristics, Journal of Humanitarian Logistic Supply Chain Management, 8(4), 2018, pp. 447-446.

13. Golledge, R. G., Path Selection and Route Preference in Human Navigation: A Progress Report, Semmering, UCTC 277, 1995.

14. Zhu, S., and Levinson, D., Do People Use the Shortest Path? An Empirical Test of Wardrop's First Principle, PLoS One, 10(8), 2015, pp. 1-18.

15. Pires, T. T., An Approach for Modeling Human Cognitive Behavior in Evacuation Models, Fire Safety Journal, 40(2), 2005, pp. 177-189.

16. Lee, D., Park, J. H., and Kim, H., A Study on Experiment of Human Behavior for Evacuation Simulation, Ocean Engineering, 31(8-9), 2004, pp. 931-941.
17. Pan, X., Han, C. S., Dauber, K., and Law, K. H., A Multi-agent Based Framework for the Simulation of Human and Social Behaviors during Emergency Evacuations, AI Society, 22(2), 2007, pp. 113-132.

18. Jumadi, A. H., Malleson, N., Carver, S., Quincey, D., and Manville, V., Modelling Individual Evacuation Decisions during Natural Disasters: A Case Study of Volcanic Crisis in Merapi, Indonesia,Geosciences, 8(6), 2018, p. 196.

19. Ding, N., and Sun, C., Experimental Study of Leader-and-follower Behaviours during Emergency Evacuation, Fire Safety Journal, 117, 2020, p. 103189.

20. Mei, E. T. W., and Lavigne, F., Mass Evacuation of the 2010 Merapi Eruption, Internatioanl Journal of Emergency Management, 9(4), 2014, p. 298.

21. Wunderman, R., Report on Merapi (Indonesia) February 2011, Bulletin of the Global Volcanism Network, 36(1), 2011.

22. Surono, Jousset, P., Pallister, J., Boichu, M., Buongiorno, M.F., Budisantoso, A., Costa, F., Andreastuti, S., Prata, F., Schneider, D., Clarisse, L., Humaida, H., Sumarti, S., Bignami, C., Griswold, J., Carn, S., Oppenheimer, C., and Lavigne, F., The 2010 Explosive Eruption of Java's Merapi Volcano-A '100-year' Event, Journal of Volcanology Geothermal Research, 241242, 2012, pp. 121-135.

23. Wasito, J. D., Kebijakan Teknis Evakuasi, Sleman, 2013. [Online]. Available: https://bpbd. slemankab.go.id/wp-content/ uploads/2013/ 12/ JALUR-DAN-RUANG-EVAKUASI-ERUPSIMERAPI.pdf.

24. Boeing, G., OSMNX: New Methods for Acquiring, Constructing, Analyzing, and Visualizing Complex Street Networks, Computers, Environment and Urban System, 65, 2017, pp. 126-139.

25. Boeing, G., Urban Street Network Analysis in a Computational Notebook, Region, 6(3), 2019, pp. 39-51.

26. Sabri, N. A. M., Basari, A. S. H., Husin, B., and Samah, K. A. F. A., The Utilisation of Dijkstra's Algorithm to Assist Evacuation Route in Higher and Close Building, Journal of Computanional Science, 11(2), 2015, pp. 330-336.

27. He, Y., Liu, Z., Shi, J., Wang, Y., Zhang, J., and Liu, J., K-shortest-path-based Evacuation Routing with Police Resource Allocation in City Transportation Networks, PLoS One, 10(7), 2015, pp. $1-23$.

28. Lu, W., Han, L.D., Liu, C., and Long, K., A Multiple-Source, Nearest Destination, Shortest Path Problem in Evacuation Assignments, COTA International Conference of Transportation Professionals 2014, April 2015, pp. 3691-3702. 